\title{
Experimental Evaluation of Position Sensorless Control on Hybrid Electric Vehicle Applications
}

\author{
Chan-Hee Choi*, Bum-Sik Kim**, Young-Kook Lee**, Jin-Hwan Jung**, and Jul-Ki Seok ${ }^{\dagger}$ \\ $\dagger^{*}$ Power Conversion Lab., Dept. of Electrical Eng., Yeungnam University, Gyeongsan, Korea \\ ** Electric-Power Conversion System Engineering Design Team, Automotive-Corporate R\&D Division, Hyundai Motor \\ Group, Hwaseong, Korea
}

\begin{abstract}
In this paper, the feasibility of applying a position sensorless control technique to hybrid electric vehicles (HEVs) is practically evaluated. The proposed position estimator has a straightforward structure with properties that combines the model and the saliency tracking-based rotor position estimation for interior permanent magnet synchronous motors (IPMSMs). The proposed method can be used in the event of sensor loss or sensor recovery to sustain continuity of operations. The developed system takes into account the estimated position transition between two distinct sensorless methods. The transition is enhanced by introducing a synchronized transition algorithm based on a single tracking observer. Extensive experimental results are presented to verify the principles and show a reliable estimation performance over the entire speed range including standstill under $150 \%$ load conditions.
\end{abstract}

Key Words: Hybrid electric vehicles, Interior permanent magnet synchronous motors, Position sensorless control, Synchronized transition algorithm

\section{INTRODUCTION}

Interior permanent magnet synchronous motors (IPMSMs) are preferred for power propulsion in electric vehicles (EVs) due to high efficiency, high power density, and wide constant power speed range [1], [2]. Torque and/or position control of IPMSMs requires measurement or estimation of both the magnet polarity and the rotor position. Position sensors are normally used for position feedback. The use of position sensors requires space, cabling, and adds a non-negligible cost. Several failures associated with the position sensor can affect the passenger's safety and the driving performance. As high reliability and maintenance-free operation are prime considerations in EV or HEV propulsion, position sensorless methods can be a viable solution. These can adaptively replace the faulty sensor in the event of sensor loss or sensor recovery to sustain continuity of operations.

Numerous sensorless methods, based on machine models and measured electrical variables, for estimating the rotor position have been proposed [3], [4]. While such methods provide adequate performance in the medium- and high-speed range, they need accurate motor electrical parameters and fail to operate at low and zero speed due to the lack of

\footnotetext{
Manuscript received Jan. 26, 2011; revised May 20, 2011

Recommended for publication by Guest Associate Editor Byoung-Kuk Lee.

$\dagger$ Corresponding Author: doljk@ynu.ac.kr

Tel: +82-53-810-2484, Fax: +82-53-810-4767, Yeungnam University

* Power Conversion Lab., Dept. of Electrical Eng., Yeungnam University, Korea

** Electric-Power Conversion System Engineering Design Team, AutomotiveCorporate R\&D Division, Hyundai Motors Group, Korea
}

observability for rotor quantities.

To overcome these limitations, sensorless control methods based on tracking the spatial position of saliencies in electric machines have been proposed [5]-[8]. These approaches inject a high-frequency (HF) signal (normally a voltage) that interacts with rotor position dependent saliencies, modulating the resulting HF stator currents, from which the rotor position can be estimated. These signal excitation techniques have been applied to PM motors for both initial rotor position estimation (including magnet polarity detection) and very low speed control.

In this regard, a couple of methods that combine the advantages of injection methods at low and zero speed, and the lower losses and simplicity of the back-EMF integration at higher speeds, have been proposed [9]-[11]. However, applications of this type of sensorless methods to HEV systems have not yet been experimentally evaluated and reported in any open literature.

The major contribution of this paper is to develop and integrate a dedicated sensorless approach to an IPMSM for HEV applications. The developed algorithm is a hybrid system of variable configuration subject to operating frequencies. A sensorless control through tracking saturation saliency is employed to achieve accurate position estimation at low speeds and standstill. Then, the sensorless operation is handed over to the voltage model at medium and high speeds. A single tracking observer-based transition method is proposed to achieve seamless transition between estimation modes. The experimental test bench is developed at the Research Laboratory of the 

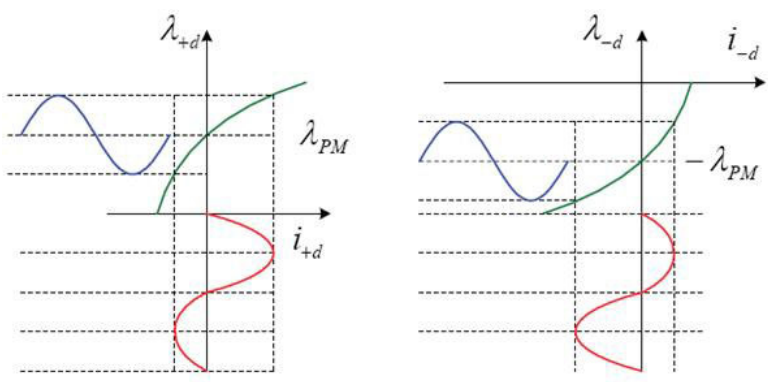

Fig. 1. Flux linkage versus applied current in the rotor reference frame.

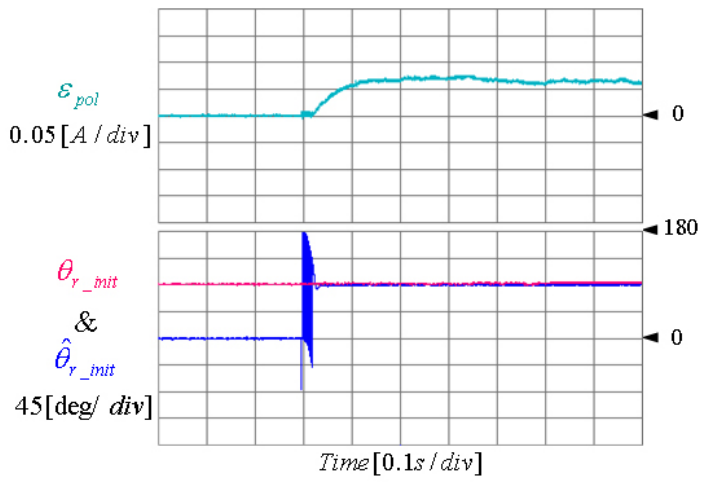

(a) $\pi / 2 \mathrm{rad}$

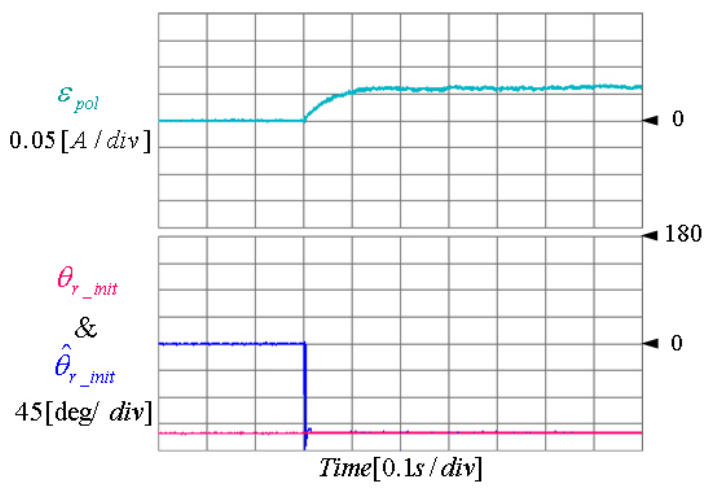

(b) $-5 \pi / 6 \mathrm{rad}$.

Fig. 2. Experimentally estimated initial rotor position.

Hyundai-Kia Motor Company in Hwasung, Korea. Compared to position-sensored systems, the results clearly demonstrate that the developed technique has comparable characteristics concerning the steady-state position estimation error in the entire operating condition.

\section{Saliency Tracking-Based Position Estimation}

In this paper, a HF pulsating sinusoidal voltage is superimposed on the fundamental excitation to create a positiondependent carrier current signal. An initial location of the magnetic axis can be estimated by using the carrier signal current resulting from the interaction between the carrier signal voltage and the spatial saliency. Rotor position is estimated by minimizing position error from the carrier current.

An IPMSM model can be represented as a complex vector form in a stationary frame as (1).

$$
\begin{aligned}
v_{d q s}^{s} & =R_{s} i_{d q s}^{s}+\frac{d}{d t}\left(\Sigma L \cdot i_{d q s}^{s}-\Delta L \cdot e^{j 2 \theta_{r}} i_{d q s}^{s *}\right) \\
& +\omega_{r} \lambda_{p m} e^{j \theta_{r}}
\end{aligned}
$$

where $\Sigma L=\frac{L_{q}+L_{d}}{2}, \Delta L=\frac{L_{q}-L_{d}}{2}$, and $i_{d q s}^{s *}$ denotes the complex conjugate of the stator current vector.

Neglecting resistive drop and back-EMF in (1), an IPMSM model for high frequency can be expressed as (2)

$$
v_{d q s}^{s}=\frac{d}{d t}\left(\Sigma L \cdot i_{d q s}^{s}-\Delta L \cdot e^{j 2 \theta_{r}} i_{d q s}^{s *}\right) .
$$

If a HF pulsating voltage in the estimated d-axis at a carrier frequency $\omega_{c}$ is injected into the IPMSM, the voltage vector can be given by

$$
v_{d q h}^{\hat{r}}=V_{h} \cos \omega_{c} t .
$$

An initial rotor position can be estimated with the resulting HF current at standstill as

$$
i_{d q h}^{\hat{r}}=\left(I_{c p}+I_{c n} e^{j 2 \theta_{e r r}}\right) \sin \omega_{c} t
$$

where $I_{c p}$ and $I_{c n}$ represent a magnitude of the HF positivesequence current and negative-sequence current, respectively. The first term in the right-hand side of (4) does not contain any position-related information, whereas the second one is amplitude modulated by the angular position of the saliency. However, the polarity detection is not available with the $2 \theta_{\text {err }}$ term in (4) because it only provides the location of the magnetic axis. Thus, the magnetization property, as shown in Fig.1, should be used to track the magnet polarity [12].

This nonlinear hysteresis curve results in a different current against the same injection voltage. The polarity information in the second-order harmonic component of the d-axis HF current can be obtained as

$$
\begin{aligned}
\varepsilon_{p o l} & =L P F\left(i_{d h}^{\hat{r}} \cos 2 \omega_{c} t\right) \\
& =-\left.\frac{1}{8} \frac{V_{h}^{2}}{\omega_{c}^{2}} \frac{d^{2} i_{d s}^{r}}{d \lambda_{d s}^{r 2}}\right|_{\lambda_{d s}^{r}=\lambda_{P M}} \cos ^{3} \theta_{e r r} .
\end{aligned}
$$

The coefficient sign in the right-hand side of (5) can be used to distinguish the polarity of the rotor magnet at the estimated position.

Fig. 2 shows the experimentally estimated initial rotor position for the tested IPMSM. The injection condition has been set to $10 \mathrm{~V}-750 \mathrm{~Hz}$. A brushless resolver attached to the motor was used to assess the actual magnet position. Two different cases were compared and a close match was found except in the transient region.

Fig. 3(a) illustrates the overall signal processing applied to the measured currents to determine the initial position and the estimate rotor position. The enhanced Luenberger style observer for tracking the rotor position provides the estimated rotor speed in addition to the estimated rotor position as shown in Fig. 3(b). This observer mitigates noise from the estimated signals and also provides zero-phase lag estimation due to the torque command feedforward [13].

\section{BACK-EMF TRACKING-BASED POSITION ESTIMATION}

Back-EMF tracking-based position estimation methods are based on the integration of the motor back-EMF to find the 


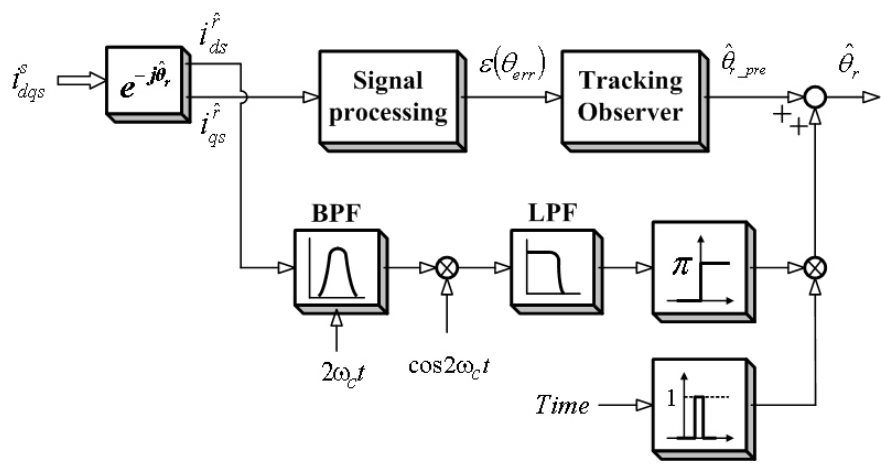

(a)

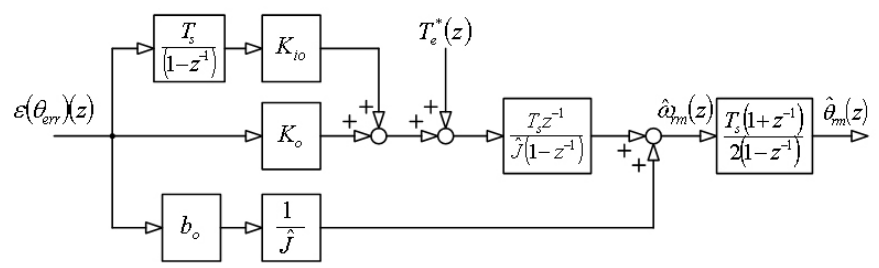

(b)

Fig. 3. Block diagram of HF signal-injection-based position estimation. (a) Overall signal processing, (b) discrete time tracking observer.

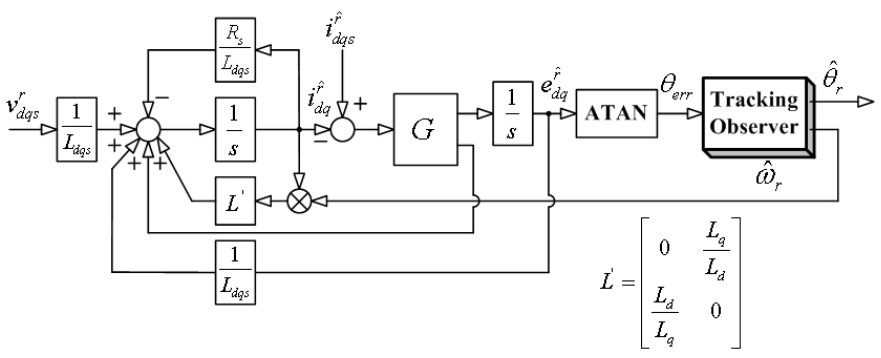

Fig. 4. Block diagram of tracking observer-based position estimation.

stator flux linkage space vector. The back-EMF is simply computed in the stationary reference frame as

$$
e_{d q r}^{s}=\left(v_{d q s}^{s *}-R_{s} i_{d q s}^{s}\right)-L_{d q s} \frac{d i_{d q s}^{s}}{d t}
$$

where $v_{d q s}^{s *}$ represents the command value of the stator voltage. An elegant way of dealing with this calculation at high speeds is to use a full order closed-loop observer. The IPMSM voltage equation of (1) can be rewritten in the rotor reference frame as

$$
\begin{aligned}
\frac{d}{d t}\left[\begin{array}{l}
i_{d s}^{r} \\
i_{q s}^{r}
\end{array}\right] & =\left[\begin{array}{cc}
-\frac{R_{s}}{L_{d}} & \frac{\hat{\omega}_{r} L_{q}}{L_{d}} \\
-\frac{\hat{\omega}_{r} L_{d}}{L_{q}} & -\frac{R_{s}}{L_{q}}
\end{array}\right]\left[\begin{array}{c}
i_{d s}^{r} \\
i_{q s}^{r}
\end{array}\right]+\left[\begin{array}{cc}
\frac{1}{L_{d}} & 0 \\
0 & \frac{1}{L_{q}}
\end{array}\right]\left[\begin{array}{l}
v_{d s}^{r} \\
v_{q s}^{r}
\end{array}\right] \\
& +\left[\begin{array}{c}
0 \\
-\frac{\hat{\omega}_{r} \lambda_{p m}}{L_{q}}
\end{array}\right] .
\end{aligned}
$$

If the position estimation error is sufficiently small, (7) can

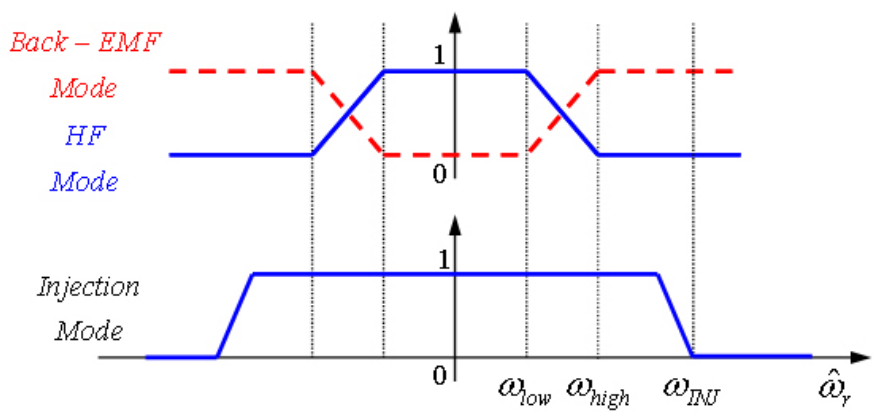

Fig. 5. Schematic diagram of sensorless mode switching.

be approximated in the estimated rotor reference frame as

$$
\begin{aligned}
\frac{d}{d t}\left[\begin{array}{l}
i_{d}^{\hat{r}} \\
i_{q}^{\hat{r}}
\end{array}\right] & =\left[\begin{array}{cc}
-\frac{R_{s}}{L_{d}} & \frac{\hat{\omega}_{r} L_{q}}{L_{d}} \\
-\frac{\hat{\omega}_{r} L_{d}}{L_{q}} & -\frac{R_{s}}{L_{q}}
\end{array}\right]\left[\begin{array}{l}
i_{d}^{\hat{r}} \\
i_{q}^{\hat{r}}
\end{array}\right]+\left[\begin{array}{cc}
\frac{1}{L_{d}} & 0 \\
0 & \frac{1}{L_{q}}
\end{array}\right]\left[\begin{array}{c}
v_{d}^{\hat{r}} \\
v_{q}^{\hat{r}}
\end{array}\right] \\
+ & {\left[\begin{array}{c}
\frac{\hat{\omega}_{r} \lambda_{p m}}{L_{q}} \sin \theta_{\text {err }} \\
-\frac{\hat{\omega}_{r} \lambda_{p m}}{L_{q}} \cos \theta_{\text {err }}
\end{array}\right] . }
\end{aligned}
$$

From (8), the rotor position error can be estimated with the arctan calculation as

$$
\theta_{e r r}=\tan ^{-1}\left(\frac{\hat{\omega}_{r} \lambda_{f} \sin \theta_{e r r}}{\hat{\omega}_{r} \lambda_{f} \cos \theta_{e r r}}\right) .
$$

As a result, this back-EMF tracking observer cascades with the enhanced Luenberger style observer in Fig. 3(b) for rotor position and velocity estimation. Fig. 4 shows the block diagram of the back-EMF tracking observer in the estimated rotor reference frame to obtain the rotor position error, where the matrix $G$ represents a full order observer gain matrix.

\section{Synchronized Transition BetweEn Both ESTIMATIONS}

Since the back-EMF-based method yields good estimations at higher speeds, it is desirable that the injection method should switch gradually to the back-EMF-based method over a certain operating frequency. However, the realization of a smooth transition is not trivial due to different estimation dynamics of both estimators. Thus, the developed algorithm takes into account the position estimator-transition smoothness in terms of estimated velocity and position transients. The main idea of the proposed transition is to use a linear combination between both position error signals, not velocity or position. The proposed transition differs from previous schemes [10], [11] in several aspects: 1) it requires a single tracking observer; 2) it does not need to design weight functions/transition parameters or adjust dual observer frequency characteristics; 3 ) mode switchover occurs during a prescribed transition period; 4) no need to reset or adjust the integrator of the tracking observer.

Fig. 5 shows the mode switching graph, where the mode switching occurs the frequency range between $\omega_{\text {low }}$ and $\omega_{\text {high }}$, and the HF signal injection ends (motoring operation) at the speed command of $\omega_{I N J}$ to reduce additional losses. During mode switching, the error signal is calculated by multiplying the mode value of Fig. 5 by each error signal estimated from Fig. 3 and 5. Then, the summation of two signals becomes the input of the tracking observer of Fig. 3(b). 


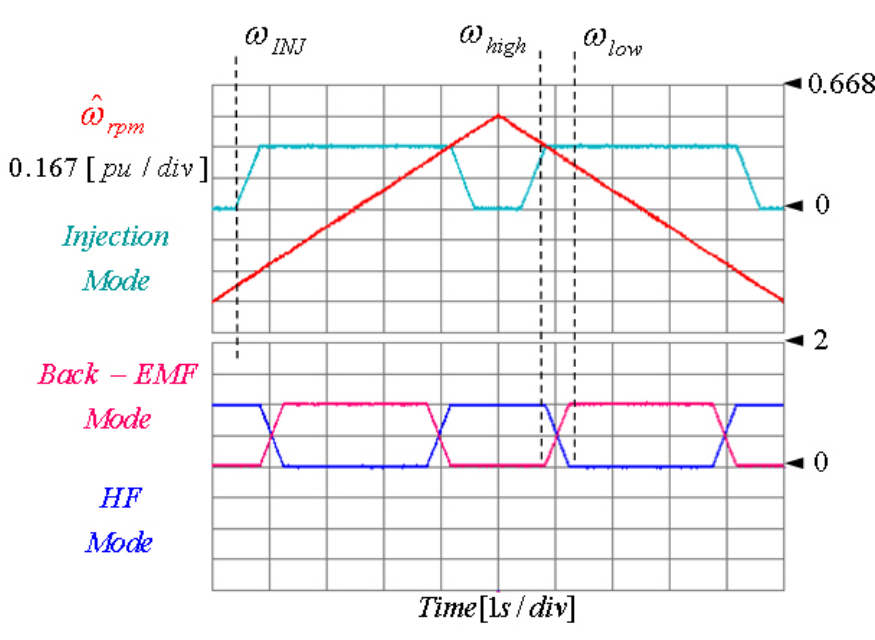

Fig. 6. Mode switching test result.

This reduces the computation burden for the position estimation during mode switching. This is advantageous as only one tracking observer needs to be developed.

Here, the transition parameters $\left(\omega_{\text {low }}, \omega_{\text {high }}, \omega_{I N J}\right)$ are irrelevant to the motor operating conditions such as temperature and external load conditions. The accurate acquisition of backEMF information only sets a lower limit of these parameters.

The performance of the proposed sensorless mode switching was confirmed by the velocity acceleration and deceleration test illustrated by Fig. 6. Here, transition period was set from $0.25 \mathrm{pu}\left(\omega_{\text {low }}\right)$ to $0.33 \mathrm{pu}\left(\omega_{\text {high }}\right)$ of the base speed and $\omega_{I N J}$ was given as $0.4 \mathrm{pu}$. Distortions are rarely found during the transition from injection to back-EMF-based estimation. This will lead to a real smooth transition with no abrupt change in the estimated position and velocity.

Fig. 7 shows the overall control block diagram of the proposed position sensorless scheme for automotive applications taking into account the wide speed operation. The rotor position estimation of HF signal injection is obtained through a signal processing method using second-order discrete-time Butterworth band-pass filters and band-stop filters.

\section{EXPERIMENTAL RESULTS}

The proposed algorithm was implemented on a $12 \mathrm{~kW}$ (maximum power) IPMSM with the $40 \mathrm{Nm}$ rated torque, as shown in Fig. 8. Two-phase currents were sampled at $50 \mu \mathrm{s}$ and the nominal deadtime was set to $1.5 \mu \mathrm{s}$. A brushless resolver was mounted to the tested motor to monitor the real rotor position and velocity. The other end of the shaft was coupled to an identical IPMSM to apply external loads. In the experiments shown in this paper, Hall-effect current sensors and 14-bit A/D converters captured the stator currents. The complex vector PI current controller was employed to achieve more stable performance at high speeds [14]. The maximum speed reaches to 5 times of the base speed and the voltage feedback-type flux weakening controller was implemented to use the full capacity of the available voltage and current [15].

The injection condition for the normal operation was fixed at $5 \mathrm{~V}-750 \mathrm{~Hz}$ in the estimated d-axis synchronous reference frame and the nominal battery voltage was set as $300 \mathrm{~V}$.
The cross-saturation effect is compensated by employing the approximated polynomial from offline tests.

The determined bandwidths for controllers and estimators used in the test are summarized in Fig. 9, where $\omega_{P_{-} o b s}$, $\omega_{c c}, \omega_{L P F}$, and $\omega_{s w}$ represent the bandwidth of the tracking observer, the current controller, the lowpass filter for the fundamental current filtering, the injection frequency, and the PWM frequency, respectively.

The test result in motoring operation of zero to the maximum speed is depicted in Fig. 10, where the estimated rotor speed, the stator current magnitude, the d-axis current, and the q-axis current are illustrated from top to bottom. The airgap torque and the motor speed of an IPMSM are controlled very well without any position sensor over the entire operating region.

Fig. 11 shows the stepwise load test results at standstill and $3.3 \mathrm{pu}$ speed. From top to bottom, the estimated speed, the position error, and the applied stepwise load torque are depicted. Here, the vertical axis of the load torque is plotted in the reverse direction. With the proposed method, it is possible to operate at zero stator frequency under $150 \%$ step load condition, as shown in Fig. 11 (a). The proposed saliency tracking-based position sensorless control satisfies the load tests of automotive applications at zero speed. The position error is within \pm 5 electrical degrees except the transient state.

Separation between fundamental wave and high frequency components is usually achieved using a band-pass/stop and a lowpass filter. This limits the bandwidth of both the current controller and the observer. Although the proposed position sensorless method is promising, more research is required to improve the transient performance of the saliency trackingbased estimation.

The performance of the proposed method is investigated through experiments under the flux weakening region, as shown in Fig. 11 (b). In this region, the rotor position is estimated through the back-EMF tracking-based sensorless approach. The test result indicates that the stable operation is sustained in the rapid-load-change condition. The position error is within \pm 5 degrees at transient state as well as steadystate.

Fig. 12 illustrates the summarized results of whole load tests in terms of the position errors over the entire speed range. From this result, it can be concluded that the performance of the proposed position sensorless control technique to hybrid electric vehicles (HEVs) is nearly comparable to that of the position sensored controller. Since the motor drive system eliminates any position sensors and cables inside the vehicle, it is significantly beneficial in terms of costs and reliability.

\section{CONCLUSIONS}

In this paper, we carry out the experimental evaluations and integrate a dedicated sensorless approach to an IPMSM for HEV applications. A combined position estimation structure for deriving the estimated rotor angle at any speed has been proposed. The hybrid structure presents a smooth transition from a nonmodel-based signal-injection method at low speed to a model-based estimation at higher speeds. The steadystate position error can be thought to be comparable to that of 


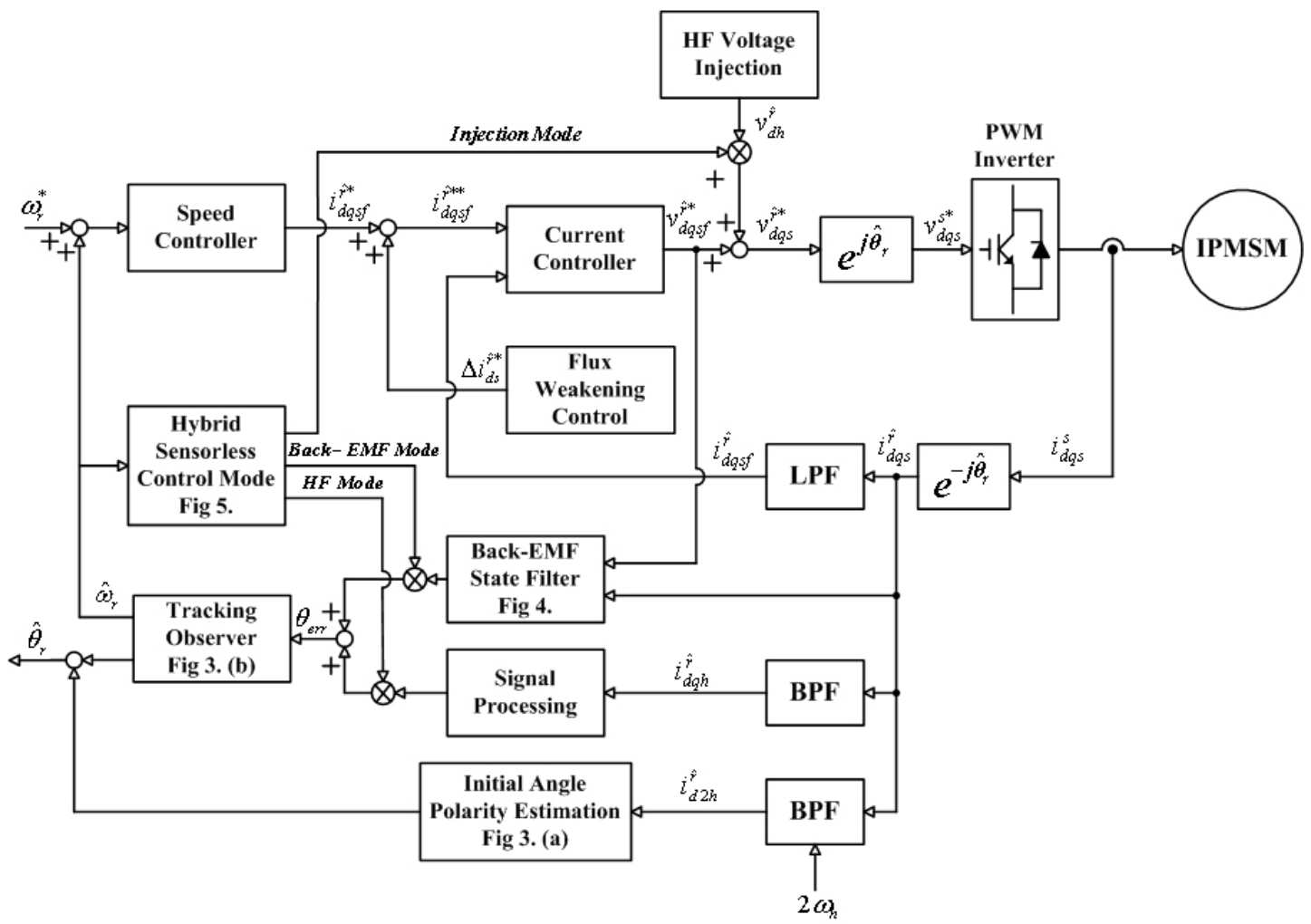

Fig. 7. Block diagram of the proposed position sensorless control approach.

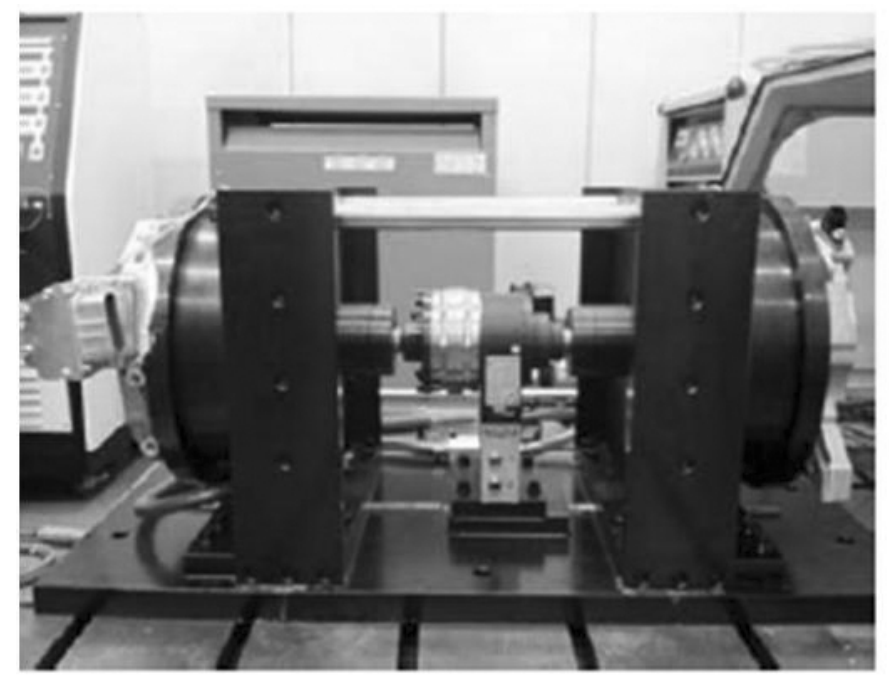

Fig. 8. Experimental test bench.

the sensored operation in the entire operating condition. The experimental test was performed by test specifications of the Hyundai-Kia Motor Company. The proposed method can be used in the event of sensor loss or sensor recovery to sustain continuity of operations.

\section{ACKNOWLEDGMENT}

This research was supported by the Yeungnam University research grants in 2010.

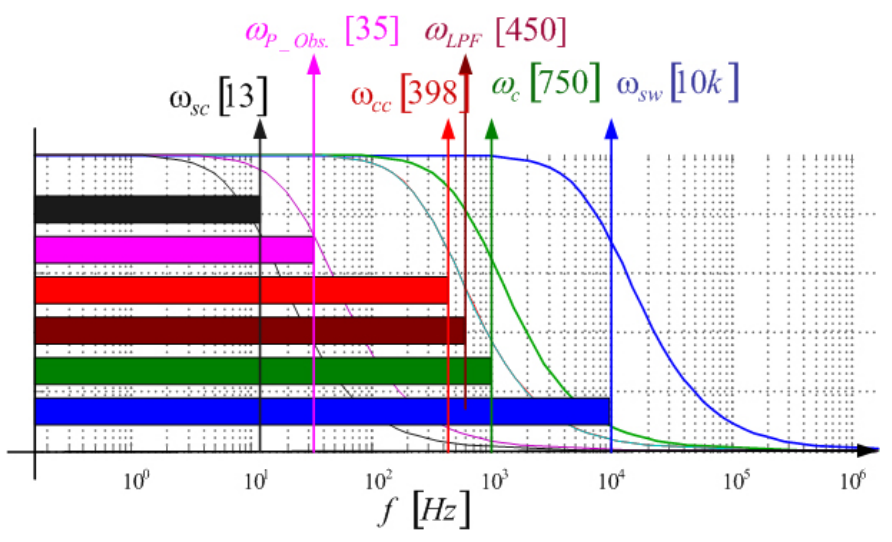

Fig. 9. Determined bandwidth used in the test.

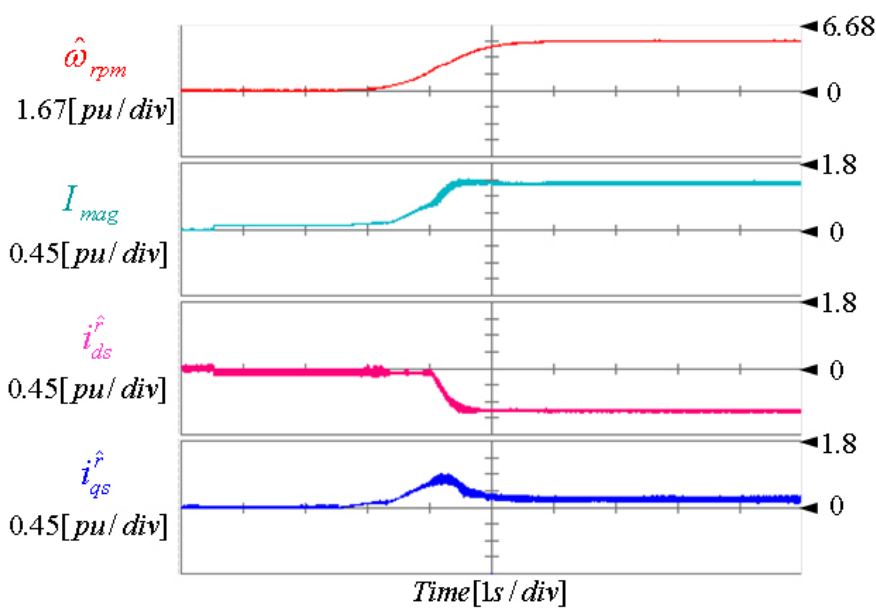

Fig. 10. Experimental result of motoring operation to maximum speed. 


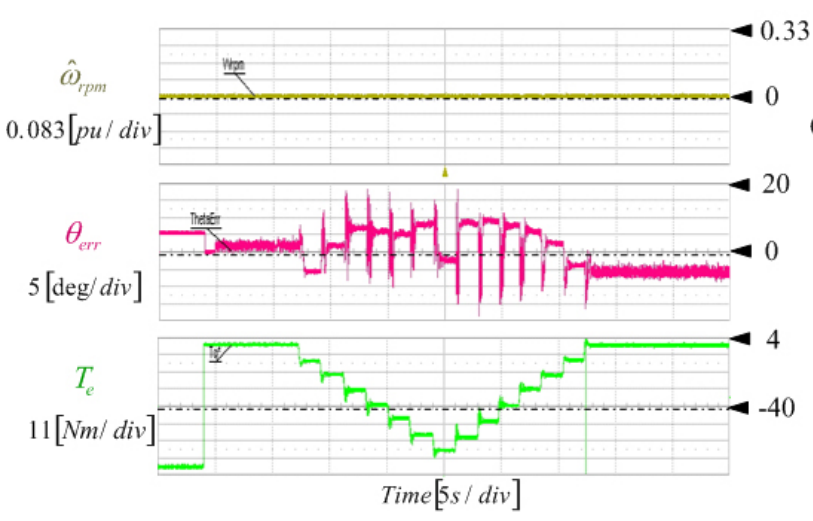

(a) $150 \%$ load test at standstill.

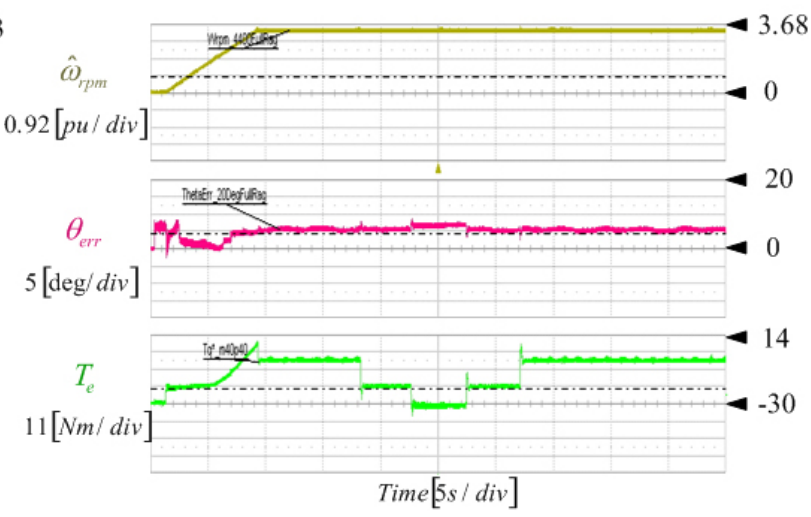

(b) Full load test at 3.3 pu of the rated speed.

Fig. 11. Step load test results.

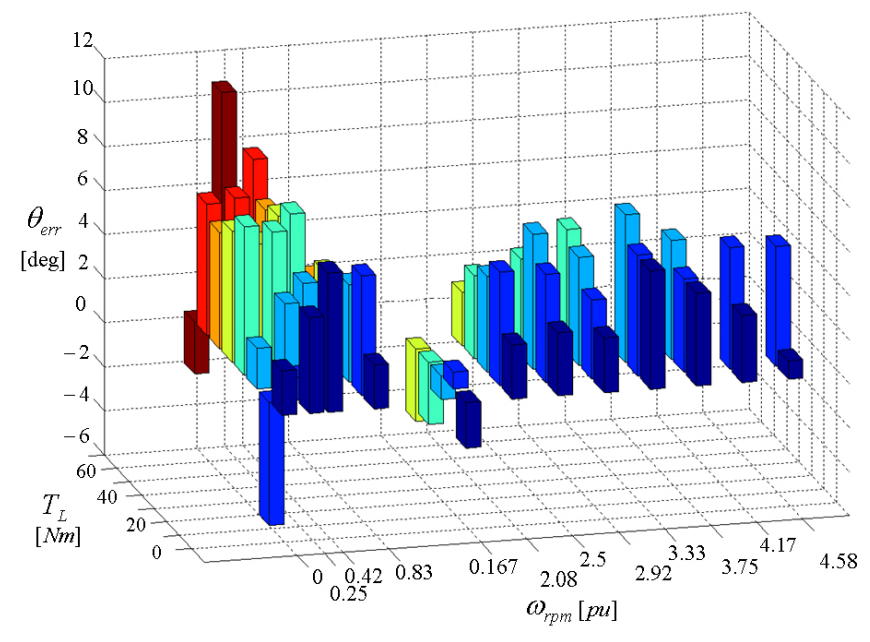

Fig. 12. Summarized results of position errors.

\section{REFERENCES}

[1] M. Hasegawa, S. Yoshioka, and K. Matsui, "Position sensorless control of interior permanent magnet synchronous motors using unknown input observer for high-speed drives," IEEE Trans. Ind. Appl., Vol. 45, No. 3, pp. 938-945, May/Jun. 2009.

[2] K. C. Kim, C. S. Jin, and J. Lee, "Magnetic shield design between interior permanent magnet synchronous motor and sensor for hybrid electric vehicle," IEEE Trans. Magn., Vol. 45, No. 6, pp. 2835-2838, Jun. 2009.

[3] H. Kubota and K. Matsuse, "The improvement of performance at low speed by offset compensation of stator voltage in sensorless vector controlled induction machines," in Proc. IEEE-IAS Annu. Meeting, pp. 257-261, Oct. 1996.

[4] J. Holtz, "Sensorless control of induction machines-With or without signal injection," IEEE Trans. Ind. Electron., Vol. 53, No. 1, pp. 7-30, Dec. 2006.

[5] P. L. Jansen and R. D. Lorenz, "Transducerless position and velocity estimation in induction and salient AC machines," IEEE Trans. Ind. Appl., Vol. 31, No. 3, pp. 240-247, Mar./Apr. 1995.

[6] J. Ha and S. Sul, "Sensorless field-orientation control of an induction machine by high-frequency signal injection," IEEE Trans. Ind. Appl., Vol. 35, No. 1, pp. 45-51, Jan./Feb. 1999.

[7] A. Consoli, G. Scarcella, and A. Testa, "A new zero-frequency flux position detection approach for direct-field-oriented-control drives," IEEE Trans. Ind. Appl., Vol. 36, No. 3, pp. 797-804, May/Jun. 2000.

[8] N. Teske, G. M. Asher, M. Sumner, and K. J. Bradley, "Suppression of saturation saliency effects for the sensorless position control of induction motor drives under loaded conditions," IEEE Trans. Ind. Electron., Vol. 47, No. 5, pp. 1142-1150, Oct. 2000.
[9] E. Capecchi, P. Guglielmi, M. Pastorelli, and A. Vagati, "Position sensorless control of the transverse-laminated synchronous reluctance motor," IEEE Trans. Ind. Appl., Vol. 37, No. 6, pp. 1768-1776, Nov./Dec. 2001.

[10] K. Ide, J. Ha, and M. Sawamura, "A hybrid speed estimator of flux observer for induction motor drives," IEEE Trans. Ind. Electron., Vol. 53, No. 1, pp. 130-137, Feb. 2006.

[11] C. Silva, G. M. Asher, and M. Sumner, "Hybrid rotor position observer for wide speed-range sensorless PM motor drives including zero speed," IEEE Trans. Ind. Electron., Vol. 53, No. 2, pp. 373-378, Apr. 2006.

[12] Y. Jeong, R. D. Lorenz, T. M. Jahns, and S. Sul, "Initial rotor position estimation of an interior permanent-magnet synchronous machine using carrier-frequency injection methods," IEEE Trans. Ind. Appl., Vol. 41, No. 1, pp. 38-45, Jan./Feb. 2005.

[13] R. W. Hejny, "Degradation of dynamic stiffness at low speeds when using back-emf tracking for closed loop speed control," MS ECE Thesis, University of Wisconsin - Madison, Madison, WI, 2008.

[14] F. Briz, M.W. Degner, and R. D. Lorenz, "Analysis and design of current regulators using complex vectors," IEEE Trans. Ind. Applicat., Vol. 36, pp. 817-825, May/Jun. 2000.

[15] T. M. Jahns, "Flux-weakening regime operation of an interior permanent magnet synchronous motor drive," IEEE Trans. Ind. Appl., Vol. IA-22, No. 4, pp. 738-747, Jul./Aug. 1987.

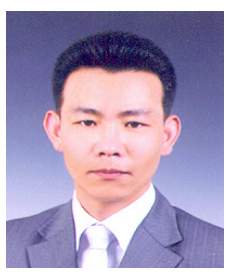

Chan-Hee Choi received the B.S. and M.S. degrees in electrical engineering from the school of Electrical Engineering, Yeungnam University, Kyungsan, Korea, in 2004 and 2007, respectively, where he is currently working toward the Ph.D. degree in the Power Conversion Laboratory. His current research interests include high-performance electrical machine drives, sensorless control of ac machines, and traction drives for hybrid electric vehicles.

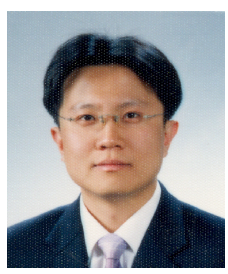

Bum-Sik Kim received the B.S., M.S. degrees in electrical engineering from Korea University, Seoul, Korea, in 2003 and 2005, respectively. He is currently a Research Engineer with the Electric-Power Conversion System Engineering Design Team, Automotive, Corporate R\&D Division, Hyundai Motor Group. His main interests are ac motor control for IPMSM, simulation, and EV/HEV motor drives. 


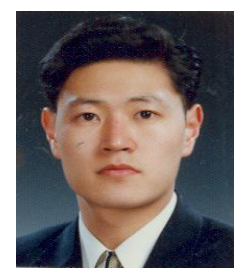

Young-Kook Lee received the Ph.D. degree from the Georgia Institute Technology, Atlanta, USA, in 2007. $\mathrm{He}$ is currently a Senior Research Engineer with the Electric-Power Conversion System Engineering Design Team, Automotive, Corporate R\&D Division, Hyundai Motor Group. His main interests are IPMSM control and fault diagnosis.

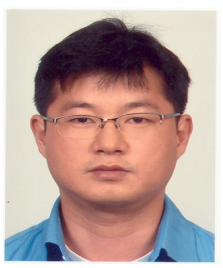

Jin-Hwan Jung received the B.S. degree from Pusan National University, Pusan, Korea, and the M.S. and Ph.D. degrees from Pohang University of Science and Technology, Pohang, Korea, in 1994, 1996, and 1999 respectively, all in electrical engineering. He is currently a Principal Research Engineer with the Electric-Power Conversion System Engineering Design Team, Automotive, Corporate R\&D Division, Hyundai Motor Group. His main interests are ac motor control for high-speed operation, EV and HEV motor drives, and power converter/inverter systems.
He received a Best Paper Award from the IEEE industrial Electronics Society in 1998 .

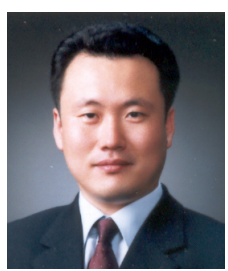

Jul-Ki Seok received the B.S., M.S., and Ph.D. degrees from Seoul National University, Seoul, Korea, in 1992, 1994, and 1998, respectively, all in electrical engineering. From 1998 to 2001, he was a Senior Engineer with the Production Engineering Center, Samsung Electronics, Suwon, Korea. Since 2001, he has been a member of the faculty of the School of Electrical Engineering, YeungNam University, Kyungsan, Korea, where he is currently an Associate Professor. His specific research interests are in high performance electrical machine drives, sensorless control of ac machines, and nonlinear system identification related to the power electronics field. Dr. Seok is currently a member of the Editorial Board of the IET Transactions on Electric Power Applications. He also serves as the current Vice Chair of the IEEE IAS-Industrial Drive Committee (IDC) Paper Award Department. 